\title{
Impact of anti-rheumatic drugs and steroids on clinical course and prognosis of COVID-19
}

\author{
Carmine Gazzaruso ${ }^{1,2}$ (D) $\cdot$ Nicoletta Carlo Stella $^{3} \cdot$ Giuseppe Mariani $^{3} \cdot$ Anna Tamburlini $^{3} \cdot$ Pietro Garini $^{3}$. \\ Elena Freddi ${ }^{3} \cdot$ Carolina Ravetto $^{3} \cdot$ Adriana Coppola $^{2} \cdot$ Pietro Gallotti $^{3}$
}

Received: 26 May 2020 / Revised: 26 May 2020 / Accepted: 11 June 2020 / Published online: 17 June 2020

(C) International League of Associations for Rheumatology (ILAR) 2020

Most of the patients with coronavirus disease 2019 (COVID19) are asymptomatic or have mild symptoms, but about 15 $20 \%$ of them experience a severe course with pneumonia that can progress to respiratory failure, cardiovascular involvement, and death [1]. Patients with mild forms of COVID-19 are usually treated at home and have a good prognosis, while those with severe disease are hospitalized and about one third of them can die [1]. Patients suffering from rheumatic diseases (RD) may be at higher infectious risk and may have a worse course of COVID-19 because of RD itself and the treatment with immunosuppressive agents, including steroids [2]. Really, recent studies showed conflicting data on incidence, hospitalization rate, and outcomes of COVID-19 among RD [3-7]. Incidence, clinical course, and prognosis of COVID-19 in RD patients are mainly attributed to disease-modifying antirheumatic drugs (DMARDs) [3-7], while the specific impact of steroids was never taken into account. Therefore, we evaluated RD patients hospitalized for COVID-19 and RD outpatients with the aim to investigate clinical course and outcomes of COVID-19. We evaluated 219 consecutive patients admitted to our hospital for SARS-CoV2 pneumonia and the last 115 patients seen in the outpatient department of

Topical Collection: Impact and Specific Considerations of COVID-19 for Clinical Rheumatologists

Carmine Gazzaruso

c.gazzaruso@gmail.com

1 Emergency Unit and Endocrinology Unit, Istituto Clinico "Beato Matteo" (Hospital Group San Donato), Corso Pavia, 84, 27029 Vigevano, Italy

2 Centre for Applied Clinical Research (Ce.R.C.A.), Istituto Clinico "Beato Matteo" (Hospital Group San Donato), Corso Pavia, 84, 27029 Vigevano, Italy

3 Internal Medicine, Oncology and Rheumatology Unit, Istituto Clinico "Beato Matteo" (Hospital Group San Donato),

Vigevano, Italy rheumatology. Among hospitalized patients, pneumonia was documented by computed tomography and infection was established by RT-PCR. All patients took their medications in addition to the treatment for COVID-19.

Table 1 shows that among hospitalized patients, only two of them had an established RD. Both had rheumatoid arthritis, were treated with hydroxychloroquine and steroids, and were discharged after recovery. Among the 115 patients attending outpatient department, 7 of them had symptoms considered by the general practitioner suggestive for COVID-19, and in one of these patients, SARS-CoV2 infection was confirmed by RT-PCR. None of them was admitted to the hospital, and all recovered after treatment with antibiotics and acetaminophen. Interestingly, none of the RD patients hospitalized for COVID-19 took DMARDs and the percentage of RD outpatients who took DMARDs was significantly lower among outpatients with that in those without COVID-19 (14.3 versus $56.5 \% ; p=0.047229)$. Among the hospitalized patients, 8 of them were taking corticosteroids ( 6 of them were taking from 5 to $12.5 \mathrm{mg}$ of prednisone and 2 patients were treated with $4 \mathrm{mg}$ of methylprednisolone) before the admission ( 2 for rheumatoid arthritis, 4 for chronic obstructive pulmonary disease, 1 for asthma, and 1 for inflammatory bowel disease). They had CRP and D-dimer lower and oxygen saturation higher than other hospitalized patients, even if the difference does not attain statistical significance. None of them died, and all were discharged after recovery.

Our data show a small incidence of COVID-19 among RD outpatients and a small presence of RD patients among subjects hospitalized for COVID-19. When COVID-19 occurred in $\mathrm{RD}$ patients, it had a better course and a good prognosis. DMARDs seem to protect against a worse prognosis, as no hospitalized patient was taking DMARDs and the percentage of RD outpatients treated with DMARDs was significantly lower among subjects with COVID-19. Interestingly, our study first shows that hospitalized patients taking steroids for RDs or other diseases may have clinical parameters and a prognosis better than other hospitalized patients. 
Table 1 Features and outcome of patients hospitalized for SARS-CoV2 disease, outpatients with rheumatic diseases, and hospitalized patients treated with steroids

\begin{tabular}{|c|c|c|c|}
\hline Variable & Hospitalized patients $(n=219)$ & Hospitalized patients without RD $(n=217)$ & Hospitalized patients with $\mathrm{RD}(n=2)$ \\
\hline Age (years) & $69.8 \pm 13.2$ & $69.7 \pm 13.2$ & $78.0 \pm 4.2$ \\
\hline Males $(\%)$ & 63.9 & 64.1 & 50.0 \\
\hline \multicolumn{4}{|l|}{ Main symptoms } \\
\hline Fever $(\%)$ & 88.1 & 88.4 & 50.0 \\
\hline Cough $(\%)$ & 31.3 & 31.8 & 0 \\
\hline Shortness of breathing (\%) & 50.1 & 50.2 & 50 \\
\hline Other $(\%)$ & 21.0 & 20.7 & 50 \\
\hline C-reactive protein $(\mathrm{mg} / \mathrm{L})$ & $160.7 \pm 228.8$ & $161.3 \pm 229.7$ & $92.3 \pm 14.4$ \\
\hline D-dimer (ng/ml) & $1303.3 \pm 4423.1$ & $1314.0 \pm 4442.1$ & $141.5 \pm 23.3$ \\
\hline Oxygen saturation $(\%)$ & $88.1 \pm 7.8$ & $88.0 \pm 7.8$ & $93.5 \pm 3.5$ \\
\hline Diabetes $(\%)$ & 18.3 & 17.5 & 100 \\
\hline Hypertension (\%) & 46.2 & 45.6 & 100 \\
\hline DMARDs $(\%)$ & 0 & 0 & 0 \\
\hline Hydroxychloroquine (\%) & 0.1 & 0 & 100 \\
\hline Steroids $(\%)$ & 3.7 & 2.8 & 100 \\
\hline Recovery $(\%)$ & 64.4 & 64.1 & 100 \\
\hline Death $(\%)$ & 35.6 & 35.9 & 0 \\
\hline Variable & Total outpatients $(n=115)$ & $\begin{array}{l}\text { Outpatients without SARS-CoV2 } \\
\quad \text { disease }(n=108)\end{array}$ & $\begin{array}{l}\text { Outpatients with SARS-CoV2 } \\
\quad \text { disease }(n=7)\end{array}$ \\
\hline Age (years) & $66.5 \pm 11.5$ & $67.1 \pm 11.2$ & $57.0 \pm 12.1$ \\
\hline Males $(\%)$ & 15.6 & 16.7 & 0 \\
\hline \multicolumn{4}{|l|}{ Main symptoms } \\
\hline Fever $(\%)$ & 5.2 & 0 & 85.7 \\
\hline Cough $(\%)$ & 4.3 & 0 & 71.4 \\
\hline Shortness of breathing (\%) & 1.7 & 0 & 28.6 \\
\hline Other $(\%)$ & 2.6 & 0 & 42.8 \\
\hline \multicolumn{4}{|l|}{ Rheumatic disease } \\
\hline Rheumatoid arthritis (\%) & 60.0 & 63.0 & 14.3 \\
\hline Spondyloarthritis (\%) & 20.9 & 21.3 & 14.3 \\
\hline Other $(\%)$ & 19.1 & 15.7 & 71.4 \\
\hline Diabetes $(\%)$ & 25.2 & 26.0 & 14.3 \\
\hline Hypertension (\%) & 59.1 & 61.1 & 28.6 \\
\hline DMARDs $(\%)$ & 53.9 & 56.5 & $14.3^{*}$ \\
\hline Hydroxychloroquine (\%) & 33.0 & 31.5 & 57.1 \\
\hline Steroids $(\%)$ & 71.3 & 73.2 & 42.8 \\
\hline Hospitalized (\%) & 0 & 0 & 0 \\
\hline Death $(\%)$ & 0 & 0 & 0 \\
\hline Variable & Hospitalized patients $(n=219)$ & $\begin{array}{l}\text { Hospitalized patients without } \\
\text { steroids }(n=211)\end{array}$ & $\begin{array}{l}\text { Hospitalized patients with } \\
\text { steroids }(n=8)\end{array}$ \\
\hline Age (years) & $69.8 \pm 13.2$ & $69.8 \pm 13.2$ & $68.5 \pm 13.2$ \\
\hline Males $(\%)$ & 63.9 & 64.4 & 50.0 \\
\hline \multicolumn{4}{|l|}{ Main symptoms } \\
\hline Fever $(\%)$ & 88.1 & 88.6 & 75.0 \\
\hline Cough $(\%)$ & 31.3 & 32.7 & 0 \\
\hline Shortness of breathing (\%) & 50.1 & 50.7 & 37.5 \\
\hline Other $(\%)$ & 21.0 & 20.4 & 37.5 \\
\hline C-reactive protein (mg/L) & $160.7 \pm 228.8$ & $164.2 \pm 232.3$ & $67.7 \pm 32.3$ \\
\hline D-dimer (ng/ml) & $1303.3 \pm 4423.1$ & $1334.4 \pm 4502.6$ & $482.2 \pm 520.4$ \\
\hline Oxygen saturation (\%) & $88.1 \pm 7.8$ & $88.0 \pm 7.9$ & $90.7 \pm 3.4$ \\
\hline
\end{tabular}


Table 1 (continued)

\begin{tabular}{llll}
\hline Diabetes (\%) & 18.3 & 17.5 & 37.5 \\
Hypertension (\%) & 46.2 & 46.4 & 37.5 \\
DMARDs (\%) & 0 & 0 & 0 \\
Hydroxychloroquine (\%) & 0.1 & 0 & 25.0 \\
Steroids (\%) & 3.7 & 0 & 100 \\
Recovery (\%) & 64.4 & 63.6 & 100 \\
Death (\%) & 35.6 & 36.4 & 0 \\
\hline
\end{tabular}

$R D$ rheumatic disease, $S A R S-C o V 2$ severe acute respiratory syndrome-coronavirus 2, DMARDs disease-modifying anti-rheumatic drugs. Statistical analysis: $t$ test after log transformation for non-normally distributed variables and exact Fisher's test for frequency comparisons

$* p<0.05$

Taken together, our study suggests that anti-rheumatic drugs may modulate inflammation and avoid a hyperinflammation that leads to severe complications and death in subjects with COVID-19 [1]. This seems be true also for steroids, even when used in diseases other than RD. In addition, it may be of interest to understand whether anti-rheumatic drugs can modulate the possible autoimmune response, recently reported in patients hospitalized for COVID-19 [8]. Our findings may have two clinical implications. First, we confirm that the withdrawal or dose reduction of anti-rheumatic drugs should always be avoided. Moreover, the association between treatment with steroids and a good prognosis may imply an early use of steroids in the treatment of SARS-CoV2 disease [9] to prevent its progression to severe forms and death, as recently suggested [10]. However, specific studies should confirm this hypothesis.

Contributors CG and PG contributed to the concept, design, and supervision of the study; the interpretation of data; and the writing of the manuscript. NCS, GM, AT, PG, CR, AC, EF contributed to the acquisition and interpretation of data and the critical revision of the manuscript.

\section{Compliance with ethical standards}

\section{Disclosures None.}

Ethics approval The study complies with the ethical standards of the institutional research committee and with the 1964 Helsinki Declaration.

\section{References}

1. Di Gennaro F, Pizzol D, Marotta C et al (2020) Coronavirus diseases (COVID-19) current status and future perspectives: a narrative review. Int J Environ Res Public Health 17(8). https://doi.org/ 10.3390/ijerph17082690
2. Favalli EG, Ingegnoli F, De Lucia O, Cincinelli G, Cimaz R, Caporali R (2020) COVID-19 infection and rheumatoid arthritis: faraway, so close! Autoimmun Rev 19(5):102523

3. Quartuccio L, Valent F, Pasut E, Tascini C, Vita S (2020, 2020) Prevalence of COVID-19 among patients with chronic inflammatory rheumatic diseases treated with biologic agents or small molecules: a population-based study in the first two months of COVID19 outbreak in Italy. Joint Bone Spine S1297-319X(20)30088-9. https://doi.org/10.1016/j.jbspin.2020.05.00

4. Ye C, Cai S, Shen G et al $(2020,2020)$ Clinical features of rheumatic patients infected with COVID-19 in Wuhan, China. Ann Rheum Dis:annrheumdis-2020-217627. https://doi.org/10.1136/ annrheumdis-2020-217627

5. Moiseev S, Avdeev S, Brovko M et al $(2020,2020)$ Rheumatic diseases in intensive care unit patients with COVID-19. Ann Rheum Dis:annrheumdis-2020-217676. https://doi.org/10.1136/ annrheumdis-2020-217676

6. Michelena X, Borrell H, López-Corbeto M et al (2020, 2020) Incidence of COVID-19 in a cohort of adult and paediatric patients with rheumatic diseases treated with targeted biologic and synthetic disease-modifying anti-rheumatic drugs. Semin Arthritis Rheum. https://doi.org/10.1016/j.semarthrit.2020.05.001

7. Cheng C, Li C, Zhao T et al (2020, 2020) COVID-19 with rheumatic diseases: a report of 5 cases. Clin Rheumatol:1-5. https://doi. org/10.1007/s10067-020-05160-x

8. Gazzaruso C, Carlo Stella N, Mariani G et al (2020, 2020) High prevalence of antinuclear antibodies and lupus anticoagulant in patients hospitalized for SARS-CoV2 pneumonia. Clin Rheumatol. https://doi.org/10.1007/s10067-020-05180-7

9. Russell B, Moss C, Rigg A, Van Hemelrijck M (2020) COVID-19 and treatment with NSAIDs and corticosteroids: should we be limiting their use in the clinical setting? Ecancermedicalscience 14: 1023

10. Dai J, Xiong Y, Li H et al $(2020,2020)$ Corticosteroid treatment in severe COVID-19 pneumonia: two cases and literature review. Clin Rheumatol. https://doi.org/10.1007/s10067-020-05172-7

Publisher's note Springer Nature remains neutral with regard to jurisdictional claims in published maps and institutional affiliations. 